\title{
Benjamin leitor de Brecht: cinema e distanciamento
}

\author{
[Benjamin reads Brecht: cinema e estrangement] \\ http://dx.doi.org/10.1590/1982-88373752
}

\section{Bruna Della Torre de Carvalho Lima ${ }^{1}$}

\begin{abstract}
The influence of Bertolt Brecht on Walter Benjamin is usually related to the assimilation of the critical Marxist tradition by the latter. The present article seeks to carry out an immanent and theoretical critique of the work of both authors, pursuing to investigate other possible aspects of this influence. On that ground, the goal is to demonstrate that the "distancing effect" (Verfremdungseffekt in German) employed by Brecht in his epic theatre plays a crucial role in the way Benjamin analyses the art of filming and appears in the four versions of the "The work of art in the age of mechanical reproduction" essay, as well as in his theory about the "aura".
\end{abstract}

Keywords: Benjamin; Brecht; cinema; theatre; distancing effect

Resumo: A influência de Bertolt Brecht sobre Walter Benjamin é comumente atribuída à assimilação da tradição de crítica marxista pelo último. O presente artigo busca realizar uma crítica imanente e teórica da obra de ambos com o fito de investigar outras faces possíveis dessa influência. Sendo assim, o objetivo é demonstrar que o "Efeito de distanciamento" (em alemão Verfremdungseffekt) utilizado por Brecht em seu teatro épico tem um papel fundamental na leitura que Benjamin fará do cinema e aparece nas quatro versões do ensaio sobre "A obra de arte na época de sua reprodutibilidade técnica", bem como na sua teoria sobre a "aura".

Palavras-chave: Benjamin; Brecht; cinema; teatro; efeito de distanciamento.

\begin{abstract}
Benjamin está aqui. Está escrevendo um ensaio sobre Baudelaire. [...] Ele usa como seu ponto de partida algo a que dá o nome de aura, que está ligada aos sonhos (devaneios). Diz ele: se você sente um olhar que lhe é dirigido, mesmo nas suas costas, você o retribui (!). A expectativa de que aquilo para que você olha o olhará de volta cria a aura. Supõe-se que isso está em decadência nos últimos tempos, junto com o elemento de culto na vida. B [enjamin] descobriu isso enquanto analisava filmes, onde a aura é decomposta pela reprodutibilidade da obra de arte. Uma carga de misticismo, embora sua atitude seja contra o misticismo. Este é o modo como o entendimento materialista da história é adaptado. É abominável. (BRECHT 2002: 8-9)
\end{abstract}

\footnotetext{
${ }^{1}$ Universidade de São Paulo, Faculdade de Filosofia, Letras e Ciências Humanas, Departamento de Sociologia. Email: bru.dellatorre@gmail.com

Pandaemonium, São Paulo, v. 17, n. 24, Dez.. /2014, 37-52
} 
Lima, B. - Benjamin leitor de Brecht

Curioso descobrir que Brecht via como "abominável" uma das teses de Walter Benjamin que é conhecida justamente por ter sido gestada sob sua influência, ao ponto de Theodor W. AdoRno (2012: 142) se referir ao ensaio “A obra de arte na época de sua reprodutibilidade técnica" de 1936 como algo no qual "se insinua efetivamente o pior de Brecht". A influência desta "polêmica pedra filosofal da Dinamarca", como Adorno (2012: 142) chegou a designar Brecht, teria levado Benjamin a "mistificar a desmistificação". No limite, a objeção dirigida a Benjamin era a mesma tanto do lado de Adorno, quanto do de Brecht. Se tinham razão, é uma questão para ser tratada mais à frente. Embora Brecht tenha achado a tese do declínio da aura abominável e suposto que por atrás do conceito de aura benjaminiano estaria uma espécie de explicação divinatória do spleen, o que interessa agora é mostrar que sua dedução advinda da análise do cinema - e aqui Adorno não estava equivocado - de fato era tributária das reflexões e práticas de Brecht. E, mais especificamente, daquela constelação de conceitos que giram em torno do V-Effekt, do alemão Verfremdungseffekt e que chamamos em português de "distanciamento", "estranhamento" ou simplesmente de "efeito $-\mathrm{V} " 2$.

Ciente dos riscos de tal escolha e de que a teoria é sempre parte da produção artística, a proposta aqui é pensar o efeito de estranhamento a partir da teoria do efeito de estranhamento que aparece em diversos ensaios de Brecht.

Segundo Brecht, o teatro tradicional, aristotélico ou dramático apresenta os fenômenos sociais como "do homem", eternos, naturais, a-históricos e transporta o espectador para dentro de uma ação. Tanto maior é seu sucesso quanto menos nos damos conta de que se trata de um palco, uma peça, uma apresentação. O objetivo é enredar o espectador na ação, de modo que só lhe reste uma apreciação contemplativa do espetáculo. A identificação, de acordo com Brecht, é uma das vigas mestras dessa estética. Sendo assim, a forma dramática apela para um público que vai ao teatro para ser seduzido, encantado, impressionado, exaltado, emocionado, distraído e iludido.

\footnotetext{
${ }^{2}$ Embora seja um dos traços marcantes de sua obra, o efeito-V não é novidade de Brecht, tendo surgido no iluminismo como uma forma de combater a religião e o Antigo Regime. Montesquieu e Voltaire o praticaram com entusiasmo. De acordo com Fredric JAMESON (2013: 63), "Brecht apresentou-nos muitas 'definições' desse termo, que parece ter migrado de 'ostranenie' ou 'estranhamento' dos formalistas russos a partir das inúmeras visitas de soviéticos modernistas como Eisenstein ou Tretiákov a Berlim.”. Não interessa no momento rastrear suas origens, mas apenas ressaltar os aspectos principais do efeito-V de modo a podermos analisar como Benjamin se apropria dele mais à frente.
} 
Lima, B. - Benjamin leitor de Brecht

O drama apresenta as relações entre os homens como relações não problemáticas ${ }^{3}$ e Brecht precisa renunciar à forma dramática para apresentar a realidade tal como ela é: problemática de ponta a ponta. O teatro épico ou narrativo contrapõe-se em muitos aspectos ao teatro dramático. Conforme destaca Iná Camargo CosTA (1998: 72):

Enquanto este, tomando o indivíduo como pontos de partida e de chegada, justifica as ações a partir dos caracteres (de sua psicologia, motivações internas, etc), o teatro épico deduz os caracteres das ações porque, ao invés de olhar para o indivíduo isoladamente, olha para as grandes organizações de que estes são parte; enquanto o drama se interessa por acontecimentos "naturais", de preferência situados na esfera da vida privada, o teatro épico tem interesse em acontecimentos de interesse público (mesmo os da vida privada), de preferência os que exijam explicação por não serem evidentes nem naturais; enquanto o drama se limita a apresentar seus caracteres em ação, o teatro épico transita dessa apresentação para a representação e desta para o comentário, tudo na mesma cena.

Brecht renuncia, então, à forma dramática para ir em busca de um teatro da era científica em que seja possível demonstrar o modelo máximo de teatro a partir de um acontecimento que pode vir a ocorrer em qualquer esquina, de um teatro de pesquisa que por meio da música de cena, da própria dramaturgia, da técnica do palco e da interpretação dos atores deixa de dissimular que não é teatro. $\mathrm{O}$ anti-ilusionismo é, assim, um de seus traços fundamentais. Para desvencilhar-se da ilusão, um de seus principais expedientes - e o que mais nos interessa aqui - é o distanciamento. Isto é, ao invés de produzir identificação, "distanciar um fato ou caráter é, antes de tudo, tirar desse fato ou desse caráter tudo o que ele tem de natural, conhecido, evidente, e fazer nascer em seu lugar espanto e curiosidade" (BRECHT 1967a: 137).

Um dos objetivos de Brecht ao contrapor o teatro épico ou narrativo ao teatro dramático ou aristotélico é apresentar o homem não só como um ser mutável em si, mas como um ser que pode transformar o que está a sua volta:

Ao estabelecer novos princípios artísticos e ao trabalhar com novos métodos de representação, devemos começar com as poderosas exigências de uma época em transformação: a necessidade e a possibilidade de remodelar a sociedade estão diante de

\footnotetext{
${ }^{3}$ Apresento aqui, seguindo a interpretação de Brecht, uma concepção mais geral e, por isso, reducionista em alguns pontos no que tange a forma dramática tradicional. Essa ideia pode, contudo, ser matizada, uma vez que Brecht, como autor de vanguarda, se apresenta a partir do rompimento radical com a tradição embora saibamos que os artistas mais importantes desse período incorporaram e desenvolveram tendências artísticas dos períodos anteriores. Conforme mostra Peter SzONDI (2011: 88), Brecht é um herdeiro do naturalismo que, por sua vez, já procurava seus heróis nas camadas inferiores da sociedade e cuja dramaturgia " - na qual a forma dramática procura sobreviver à crise determinada pela história - já se encontra, desde sempre, ante o perigo de reverter ela própria em épica”.
}

Pandaemonium, São Paulo, v. 17, n. 24, Dez.. /2014, 37-52 
Lima, B. - Benjamin leitor de Brecht

nós. Todos os acontecimentos entre os homens devem ser notados, e tudo deve ser visto de um ponto de vista social. Entre outros efeitos que o novo teatro necessitará para sua crítica social e seu relato histórico das transformações efetuadas, está o efeito de distanciamento (BRECHT 1967b: 114).

Se o teatro dramático fala de grandes homens (não é qualquer um que pode ser um herói dramático, conforme nos alerta Iná Camargo CosTA (1998: 57)), apenas pelo fato de ser um teatro que diz respeito a cenas e personagens comuns (qualquer um pode contar uma história ou representá-la, para Brecht) e por narrar a ação ao invés de encarná-la, o teatro épico, por sua vez, produz estranhamento. De acordo com Peter SzONDI (2011: 117), "no teatro épico, ao contrário [do teatro aristotélico] - e conforme as suas intenções científico-sociológicas -, reflete-se sobre a 'infraestrutura' social das ações em sua alienação coisificada". A reificação é, nesse sentido, escolhida por Brecht como "método" representacional e dramático. A escolha da narrativa em detrimento da forma dramática de teatro está ligada justamente a esse método, pois enquanto na última cada cena serve à outra, na primeira, cada cena vale por si mesma. Uma narrativa pode, dessa forma, ser repartida, enquanto a forma dramática tradicional pede a manutenção da unidade da forma. Na medida em que o tempo - qualitativo e não-quantificável - sofre, com a reificação, um processo de espacialização e uniformização, a narrativa deve problematizar, em sua forma, o novo formato do tempo no qual decorre a história. Se formos reler a frase de LUKÁCS (2003: 204-205), no qual essa ideia aparece de certa forma resumida, as coisas podem ficar mais claras:

\begin{abstract}
A atitude contemplativa diante de um processo mecanicamente conforme às leis e que se desenrola independentemente da consciência e sem a influência possível de uma atividade humana, ou seja, que se manifesta como um sistema acabado e fechado, transforma também as categorias fundamentais da atitude imediata dos homens em relação ao mundo: reduz o espaço e o tempo a um mesmo denominador e o tempo ao nível do espaço. [...] Nesse ambiente em que o tempo é abstrato, minuciosamente mensurável e transformado em espaço físico, um ambiente que constitui, ao mesmo tempo, a condição e a consequência da produção especializada e fragmentada, no âmbito científico e mecânico, do objeto de trabalho, os sujeitos do trabalho devem ser igualmente fragmentados de modo racional.
\end{abstract}

Tal como podemos, num mundo dominado pela reificação, repartir o tempo em partes iguais, as partes recortadas da narrativa se autonomizam em relação ao todo e, liberadas da unidade da forma, podem demonstrar o caráter histórico daquela unidade que antes parecia natural e, ao mesmo tempo, problematizar a aparência da atividade humana 
Lima, B. - Benjamin leitor de Brecht

como um "sistema acabado e fechado", isto é, a própria desarticulação produzida na sociedade (e nas obras) pelo processo de reificação. A autonomização estética permite, destarte, refuncionalizar suas partes. Esse procedimento - vanguardista por excelência remete à ideia da montagem. Reapresentadas de maneira diversa, as partes de uma narrativa podem produzir mais de um sentido e, formalmente, esse procedimento mostra que as coisas são passíveis de mudança. Ao invés de - como no teatro aristotélico colocar a tensão das cenas a serviço do desenlace da história, o teatro épico redireciona essa tensão para o próprio andamento da cena. O tempo linear da ação do drama como uma sequência de presentes idênticos é rompido na medida em que a ação torna-se o próprio objeto da narrativa. Além disso, o princípio da montagem, ao fazer surgir uma síntese intuitiva de uma imagem, inclui o espectador no processo de criação, impele-o a tomar decisões e a refletir não somente sobre os temas propostos por uma peça, mas por seu próprio desenvolvimento, rompendo com uma postura meramente contemplativa. Tal como destaca JAMESON (2013: 72), trata-se de uma espécie de minimalismo que não deixa de se remeter à megaestrutura.

Mas, afinal, como produzir esse distanciamento? Segundo Brecht, há inúmeras formas de fazê-lo. Uma maneira de não se identificar com a personagem que representa, por exemplo, é fazer com que o ator ponha o foco narrativo fora dela. Cita-se a personagem representada, ao contrário de vivenciá-la em todas as suas determinações como se tratasse de anular qualquer distância entre o ator e a personagem. Ou seja, "o objetivo do artista é parecer estranho e, mesmo, surpreendente para a plateia. Ele o consegue, olhando com estranheza para si próprio e para seu trabalho. O resultado é que tudo o que produz tem o toque de espanto" (BRECHT 1967b: 106).

$\mathrm{O}$ distanciamento ou efeito- $\mathrm{V}$ tem alguns desdobramentos. Trata-se, antes de tudo, de tornar aquilo que é familiar estranho por meio do uso de técnicas - na maioria das vezes de encenação - através das quais as coisas podem ser de fato "estranhadas", seguindo a ideia de que "a aceitação ou rejeição de suas ações e sofrimentos deviam tomar lugar no plano da consciência, em vez de, como de hábito, no subconsciente da plateia" (BRECHT 1967b: 105). Os recursos do coro e do epílogo, por exemplo, muitas vezes são utilizados com esse propósito nas peças de Brecht. Ao invés de conservar sentimentos produzidos pelo espetáculo, o objetivo é impelir ao conhecimento. Pôr um fim à simpatia e à empatia tanto do ator com relação à personagem, quanto do espectador com relação à personagem e ao ator é também um desdobramento 
Lima, B. - Benjamin leitor de Brecht

importante deste efeito. Finalmente, conforme ressalta JAMESON (2013: 65), trata-se de colocar sob nova luz todos os desdobramentos acima, segundo os quais "o familiar ou habitual é novamente identificado como o 'natural', e seu estranhamento desvela aquela aparência, que sugere o imutável e eterno, e mostra que o objeto é 'histórico'. A isso se deve acrescentar como corolário político, feito ou construído por seres humanos e, assim, também pode ser mudado por eles ou completamente substituído”.

A obra de arte, em sua forma e conteúdo, é produto de escolhas e decisões específicas. Quando o artista se depara com o material, ele tem pela frente um número infinito de escolhas possíveis no que tange à sua elaboração. No entanto, quando as escolhas são feitas e a obra se apresenta como um artefato, um objeto pronto, essas escolhas possíveis desaparecem completamente e não é possível pensar um novo começo ou um desenlace diverso para uma peça ou um romance, por exemplo. Uma das configurações do efeito de distanciamento em Brecht pode ser entendida como uma opção consciente do artista de deixar às vistas e às claras essas possíveis escolhas que rondaram a composição artística e que permitem contestar sua objetivação (reificação?), pois induz o leitor ou a plateia a perguntar se as coisas poderiam ter ocorrido de outra maneira, na medida em que confere material para isso. Desta maneira, a arte apresentase como um imenso reino do possível e, como tal, contrapõe-se à vida real, ao mesmo tempo, problematizando-a. Mas, ao invés de levar o espectador, através da ilusão, para um mundo distante, aproxima-o do mundo. Conforme afirmou BRECHT (1967b: 111), "porque não deveria a arte, com seus próprios meios naturalmente, contribuir para a grande tarefa social de dominar a vida?". Da mesma forma que mostra que a obra de arte poderia ter outras saídas, o efeito de estranhamento é capaz de criar no seu interlocutor a mesma impressão com relação à história e ao mundo social.

Todas essas ideias germinaram em Benjamin e seus frutos foram bastante controversos. Como vimos, Adorno e Brecht acusaram-no de recair no misticismo, mesmo que tentando liquidá-lo. Fredric JAMESON (2013: 65) chega a afirmar que Benjamin levou a questão do distanciamento muito mais longe na direção da metafísica do que o próprio Brecht. De fato, este último o havia impressionado.

Em “O autor como produtor", escrito em 1934, Benjamin reflete sobre as possibilidades de uma análise materialista da literatura, bem como sobre o lugar do escritor no interior da instituição literária e de sua relação com ela, de modo a definir a técnica literária como algo capaz de superar a ideia de forma e a ideia de tendência tão 
Lima, B. - Benjamin leitor de Brecht

em voga no debate soviético do período. A primeira tarefa do escritor moderno, na concepção de Benjamin, deveria ser algo diverso; a saber, tomar consciência de sua própria pobreza de experiência (pobreza esta que é histórica) e da necessidade da consciência dessa pobreza para a construção de uma nova arte. De acordo com Benjamin (1988: 105), atingir determinado ponto do progresso técnico na literatura mudaria a própria função das formas artísticas. Brecht seria, nesse aspecto, um exemplo do escritor que compreenderia que a tendência certa em termos de política no âmbito da arte é algo imanente e diz respeito à tendência certa em termos de forma. Ao contrário de manter a ilusão inerente à obra de arte tradicional e de alimentar o público com sentimentos, mesmo que esses sentimentos sejam de revolta, Brecht preferiria causar estranhamento no público por meio de uma reflexão acerca da situação em que vive. Sendo assim, BENJAMIN (1994a: 133) afirma que

Com o princípio da interrupção, o teatro épico adota um procedimento que se tornou familiar para nós, nos últimos anos, com o desenvolvimento do cinema e do rádio, da imprensa e da fotografia. Refiro-me ao procedimento da montagem: pois o material montado interrompe o contexto no qual é montado. [...] A interrupção da ação, que levou Brecht a caracterizar seu teatro como épico, combate sistematicamente qualquer ilusão por parte do público. Essa ilusão é inutilizável para um teatro que se propõe tratar os elementos da realidade no sentido de um ordenamento experimental.

Benjamin passa a se interessar pelo modo como o teatro épico conjuga e, ao mesmo tempo, chama a atenção para a estreita relação entre desenvolvimento técnico e transformação política. Em outras palavras, a forma estética de um período aristocrático deve ser diversa da forma artística de um período revolucionário. E essas transformações - que não dizem respeito apenas à política, mas às formas estéticas são fundamentais para a compreensão dessa teoria de uma nova fase da arte que Benjamin ensaia nos textos que escreve a partir de 1931. Em "Que é o teatro épico: um estudo sobre Brecht", de 1931, é possível conferir como as ideias acima expostas já aparecem de certo modo formuladas.

As formas do teatro épico correspondem às novas formas técnicas, o cinema e o rádio. Ele está situado no ponto mais alto da técnica. Se o cinema impôs o princípio de que o espectador pode entrar a qualquer momento na sala, de que para isso devem ser evitados os antecedentes muito complicados e de que cada parte, além do seu valor para o todo, precisa ter um valor próprio, episódico, esse princípio tornou-se absolutamente necessário para o rádio, cujo público liga e desliga a cada momento, arbitrariamente seus alto falantes. O teatro épico faz o mesmo com o palco. (BENJAMIN 1994b: 83)

Pandaemonium, São Paulo, v. 17, n. 24, Dez.. /2014, 37-52 
Lima, B. - Benjamin leitor de Brecht

Esses temas são desenvolvidos ao longo dos anos de 1930 paralelamente à questão da aura - para voltar à polêmica do início do texto - para depois serem conjugados por Benjamin na sua tese sobre o cinema e a reprodutibilidade técnica.

A primeira vez que a noção de aura aparece para designar uma qualidade estética na obra de Benjamin é em 1931 na "Pequena História da Fotografia". Ela é desenvolvida em “A obra de arte...” (1935/1936 e 1939) e aparece reformulada em 1939 com o texto "Sobre alguns temas em Baudelaire". Esse conceito aparece na obra de Benjamin já a partir do prisma de seu declínio e num momento de inspiração marxista de sua obra. É fundamental, por essa razão, destacar que a noção de aura na concepção de Benjamin precisa ser compreendida no entrecruzamento desses diferentes textos para que a formulação de aura presente em "A obra de arte..." não seja tomada como definitiva.

Entre fins de 1935 e início de 1936, Benjamin escreve o famoso ensaio "A obra de arte na época de sua reprodutibilidade técnica" ${ }^{4}$. Nesse ensaio, ele divide a história da arte em dois períodos. O primeiro seria definido pela noção de "aura", em suas palavras, "um espectro singular, composto de espaço e tempo: aparição única de algo distante, não importa quão próxima ela esteja" (BENJAMIN 1991: 440). A obra de arte aurática pertence, segundo seu argumento, a uma forma ritual, ainda que esse seja não um ritual religioso, mas sim secularizado nas formas de culto ao Belo ou na doutrina da "arte pela arte". Suas exigências de autenticidade e de originalidade exprimem o caráter sagrado da arte e da experiência estética e seu enraizamento na tradição. Essa autenticidade remete justamente ao caráter primitivo da arte: como ritual e culto. A reprodutibilidade técnica - o segundo momento - viria para desvelar de uma vez por

\footnotetext{
${ }^{4}$ Susan BUCK-MORSS (2012) lembra que esse texto foi escrito de certa forma como uma contraposição à estética fascista. Há quatro versões deste texto. Três delas estão em alemão e uma está em francês. Embora não seja possível levar a cabo a necessidade de apresentar esse texto aqui fazendo jus à complexidade de sua constituição, vale comentar alguns fatos relativos à sua elaboração: Benjamin buscou primeiramente, sem obter sucesso, publicar a primeira versão do texto escrita entre 1935/36 em alemão na revista russa Internationale Literatur/Deutsche Blätter. A única versão publicada de "A obra de arte na época de sua reprodutibilidade técnica" foi a francesa, traduzida por Benjamin e Pierre Klossowski a partir de duas versões em alemão escritas também entre 1935 e 1936. O texto foi entregue a Max Horkheimer para ser publicado na revista do Instituto de Pesquisa Social e este, por sua vez, fez vários cortes no texto, de modo a suavizar-lhe o vocabulário marxista, o que causou uma série de tensões entre ele e os membros do Instituto, principalmente entre Adorno e Benjamin. A segunda versão do texto foi encontrada apenas em 1989 no arquivo Horkheimer, em Frankfurt, e a quarta versão data de 1938/39. Esta última foi reescrita por Benjamin neste período e procurava condensar suas posições acerca da relação entre as possibilidades técnicas do cinema e a política de esquerda e que foi antecedida por esforços para traduzir o texto para o inglês. (Cf. SCHÖTTKER, 2012). Trabalharei, aqui, com a primeira e a segunda versão, nas quais ele mais desenvolve a questão da aura, embora uma apreciação completa do tema envolva repassar todos os momentos de produção do texto.
}

Pandaemonium, São Paulo, v. 17, n. 24, Dez.. /2014, 37-52 
Lima, B. - Benjamin leitor de Brecht

todas, segundo Benjamin, a ilusão de autonomia da arte ao liberá-la de seu contexto de utilização ritual e de seu caráter mágico. A experiência coletiva da obra de arte, proporcionada pela reprodutibilidade, desencadearia, segundo Benjamin, uma crise nas formas tradicionais de recepção.

Mas o que interessa ressaltar aqui é que a função social da arte, de acordo com essa tese de Benjamin, se transforma quando a questão da autenticidade, do "aqui e agora" da obra de arte - isto é, quando sua aura - deixa de fazer sentido; em vez de fundar-se no ritual, ela passa a encontrar seu fundamento na política. $\mathrm{O}$ valor tradicional do patrimônio da cultura é, assim, liquidado nesse contexto, pois a reprodução da obra de arte destaca-a da tradição, assim como a montagem destaca as partes do todo.

O cinema foi eleito por Benjamin, nesse âmbito, como a forma artística mais característica do período, uma vez que o seu público era a massa, ao contrário do público da literatura e da pintura: o indivíduo. A fruição coletiva de um filme poderia, de acordo com essa concepção, ter uma função mobilizadora para a política por meio dos procedimentos de choque e distanciamento permitidos pela constante movimentação da câmera que romperia, por sua vez, com a atitude contemplativa. A montagem, elogiada por Benjamin não só como procedimento próprio do cinema, mas das vanguardas - em especial do dadaísmo e do surrealismo - e do teatro épico de Brecht, trazia consigo um novo ritmo e uma nova forma de percepção, coletiva e fundada no prazer de ver e sentir, em contraposição à fruição individual e à atitude do especialista frente à obra de arte aurática. Benjamin tinha em mente o fato de que o cinema exigia uma nova forma de percepção distraída e leve, mas rápida o suficiente para acompanhar a sequência de cenas.

Mas, afinal, de que maneira apareceria a questão do efeito-V no ensaio de Benjamin? Em primeiro lugar, a reprodutibilidade técnica seria capaz de livrar, de acordo com Benjamin, a arte de seu "valor de culto" e de seu "valor eterno". Se por muito tempo as obras de arte tiveram um caráter secreto, isto é, somente alguns sacerdotes tinham acesso às esculturas de divindades, a obra de arte despida de sua função ritual é liberada para exposição. Qualquer um pode partilhar de sua fruição. Se para os gregos, que valorizavam o eterno (também devido à determinação material de que não possuíam técnica suficiente para produzir obras de arte reproduzíveis), a escultura era a forma de arte mais valorizada - pois a mais imperfeita e não reproduzível - hoje a escultura estaria em declínio. Assim como Brecht buscava 
Lima, B. - Benjamin leitor de Brecht

contrapor ao "eterno humano" do teatro dramático o homem histórico do teatro épico, Benjamin valoriza a reprodutibilidade técnica enquanto aquela que põe fim ao "eterno" da arte em geral.

Além disso, há ainda diversos momentos em que podemos observar a influência das ideias de Brecht. O cinema tem um forte cunho narrativo: a imagem é capaz de transmitir pensamentos, animar objetos e paisagens, etc. É a câmera que exercerá nele a função narrativa (ou, se quisermos, daquele sujeito fictício dos enunciados) ao focalizar a imagem, ao aproximá-la, distorcê-la, recortá-la, ao fazer um close up, etc. Benjamin compara o cinema ao teatro: enquanto no último a presença do palco como ponto de observação permite que o caráter ilusório de uma cena seja preservado, no primeiro essa natureza ilusionista aparece como algo de segunda ordem. Ao penetrar no âmago da realidade com seus aparelhos, o cinema faz parecer esse real como a realidade pura, sem a intervenção da máquina, o que contraditoriamente, faz aparecer o caráter artificial dessa montagem. Então, o narrador do filme que se expressa por meio mecânico - a câmera - assume mais de uma posição, inclusive de ordem física, na narração. Mas justamente por poder assumir diversos pontos de vista, esse narrador é de certo modo diferente do narrador do teatro ou do romance. Isso fica mais claro quando Benjamin (1991: 495-496) compara o pintor e o cinegrafista ao mágico e o cirurgião:

\begin{abstract}
Aqui a questão é como comparar o cameraman com o pintor? Para responder a essa pergunta recorreremos a uma analogia com uma operação cirúrgica. $\mathrm{O}$ cirurgião representa o polo oposto ao do mágico. O mágico cura uma pessoa doente pela imposição de suas mãos; o cirurgião corta o corpo do paciente. O mágico mantém a distância natural entre o paciente e ele próprio, e, embora a reduza muito sutilmente pela imposição das mãos, ele a aumenta em muito por sua autoridade. $O$ cirurgião faz exatamente o inverso; ele diminui em muito a distância entre ele mesmo e o paciente ao penetrar no corpo do paciente, e aumenta-a levemente pelo cuidado com que sua mão se move entre os órgãos. Em suma, em contraste com o mágico - que está ainda oculto no mágico -, o cirurgião no momento decisivo abstém-se de encarar o paciente de homem para homem; ao invés disso, é através da operação que ele o penetra. Mágico e cirurgião são comparáveis ao pintor e ao cameraman. O pintor mantém em seu trabalho uma distância natural da realidade, o cameraman penetra profundamente em sua trama.
\end{abstract}

Se formos ler a citação acima de modo cuidadoso, poderíamos inferir que o cameraman, na leitura que Benjamin faz do cinema, possuiria uma natureza brechtiana, embora diversa daquela própria ao teatro, à pintura e à literatura, pois, devido às suas potencialidades técnicas, chegaria a anular um possível distanciamento em nome da penetração radical entre narrativa cinematográfica e realidade, que constituiria de fato o 
Lima, B. - Benjamin leitor de Brecht

verdadeiro distanciamento. Daí Jameson afirmar, conforme destacado acima, que Benjamin leva o efeito- $\mathrm{V}$ a patamares mais metafísicos que Brecht. Ao fazer isso, o cinema seria a única arte capaz de fato de revelar o afirmado que não aparece na superfície, mas está lá realmente.

Os recursos auxiliares da câmera, como o zoom, as ampliações, as acelerações, revelariam, de acordo com Benjamin, o inconsciente ótico, bem como a psicanálise teria revelado o inconsciente pulsional. Mas qual é a importância disso? A importância disso está no fato de que, para Benjamin, a câmera pode registrar aspectos da realidade que se situam fora da percepção sensível comum. Por essa razão o cinema teria traços oníricos e mesmo psicóticos, pois traria à consciência coletiva àquilo que antes era da esfera individual do sonhador ou do psicótico e ao desenvolver artificialmente - por exemplo fantasias sadomasoquistas, impediria seu desenvolvimento individual, "natural" e, por isso mesmo, perigoso, ao expô-los publicamente ao estranhamento da plateia. Eis a razão pela qual BENJAMIN (1991: 499) afirma que o cinema americano produziria uma explosão terapêutica do inconsciente:

\begin{abstract}
Através de close-ups das coisas ao nosso redor, enfocando detalhes ocultos de objetos familiares, explorando ambientes - clichê sob a engenhosa condução da câmera, o filme, de um lado, amplia nossa compreensão das necessidades que regem nossa vida; de outro lado, ele nos proporciona um imenso e inesperado campo de ação. Nossas tavernas e ruas metropolitanas, nossos escritórios e salas mobiliadas, nossas estações ferroviárias e nossas fábricas parecem ter-nos confinado inapelavelmente. Então veio o filme e explodiu esse mundo-prisão com a dinamite do décimo segundo, de tal forma que agora, em meio a suas ruínas e destroços, nós calma e aventurosamente viajamos. Com o close-up, o espaço se expande, assim como o movimento com a câmera lenta. A ampliação de um instantâneo não torna simplesmente mais preciso o que de qualquer maneira era visível, apesar de obscuro: ele nos revela formações estruturais inteiramente novas do assunto. Portanto, também a câmera lenta não apenas apresenta qualidades conhecidas de movimento, como revela neles outros inteiramente desconhecidos "que, longe de parecer movimentos rápidos retardados, dão o efeito de singulares e sobrenaturais movimentos de deslizamento e flutuação. [Rudolph Arnheim]. Evidentemente uma natureza diferente abre-se à câmera mais do que ao olho nu.
\end{abstract}

A câmera, assim como a colagem, destaca um objeto de seu contexto original naturalizado e ao fazer isso destrói a aura ou a magia que consiste em fazer parecer que as coisas, seja a composição de uma obra de arte, seja de um interior burguês, não poderiam ser de outra maneira. Num raciocínio limite, poder-se-ia afirmar que o cinema é, para Benjamin, uma arte a serviço do esclarecimento, ao dar cabo à magia aurática. Desse modo, Benjamin demonstra também que não é só na estética, mas na sociologia 
Lima, B. - Benjamin leitor de Brecht

que o cinema aparece como fenômeno original. Vale lembrar aqui a ideia de Marx de que todo fetichismo e toda reificação são também uma forma de esquecimento dos processos pelos quais uma coisa veio a ser como é. Daí a necessidade que Benjamin partilhava com Brecht de buscar um rompimento com o fetichismo na arte através do fim de seu caráter ilusório. Aliás, o próprio método de escrita de Benjamin, que arranca frases de seu contexto original e constrói-se de modo aforístico na maioria de seus textos está ligado a isso e demonstra o imenso impacto que os procedimentos de vanguarda tiveram na crítica literária e na teoria social produzidas por ele.

Se é possível afirmar que, apesar de seu caráter sui generis, a obra de Brecht, ao conferir tamanho destaque em sua obra ao efeito-V, é um momento fundamental da arte de vanguarda ao dessacralizar, desnaturalizar, pôr fim à contemplação estética passiva e apassivadora e desautomatizar a atenção embotada pela rotina, podemos também afirmar que é nesse espírito que Benjamin compreende o cinema no ensaio aqui apresentado. Embora seja preciso deixar claro que se trata de uma poderosa inspiração e não de uma transposição das ideias de Brecht para a análise do cinema. Só para citar um exemplo, poderíamos destacar que Benjamin dá pouco destaque em seu ensaio à questão da identificação, tão importante para a formulação da questão do distanciamento em Brecht e que será também fundamental para a análise da indústria cultural que Adorno empreenderá junto com Max Horkheimer.

No entanto, apesar de seu entusiasmo com a reprodutibilidade técnica, BENJAMIN (1989: 630-631) matiza sua posição no final da vida ao comparar o ritmo do cinema ao ritmo do trabalho:

Assim a técnica submeteu o sensorial humano a um treinamento de natureza complexa. Chegou o dia em que o filme correspondeu a uma nova e urgente necessidade de estímulos. No filme, a percepção sob a forma de choque faz valer-se como princípio formal. Aquilo que determina o ritmo da produção na linha de montagem subjaz no filme ao ritmo da recepção.

A crença no potencial de determinados procedimentos entrava em crise. Embora estejamos falando de 1939, aquilo que ficou conhecido como a "rotinização"s do

\footnotetext{
${ }^{5}$ Antonio Candido (2008) explica o processo de normalização e penetração do modernismo na vida cultural brasileira através do conceito do sociólogo Max Weber, mas acredito que seu conceito sirva também para explicar o processo de rotinização das vanguardas como um todo. Weber utiliza a noção de "rotinização" para analisar o modo como algo efêmero, que é o carisma, na visão do sociólogo, pode se perpetuar na forma de uma dominação estendida sob outras formas. Trata-se de explicar como algo que

Pandaemonium, São Paulo, v. 17, n. 24, Dez.. /2014, 37-52
} 
Lima, B. - Benjamin leitor de Brecht

modernismo já mostrava seus sinais e a redução do horizonte de expectativa potencializada pelo início da derrocada da União Soviética e da ascensão do nazismo que ganhava forças levaram Benjamin a duvidar das potencialidades do cinema. Conforme destaca Roberto SCHWARZ (1999: 125), “por mais que a nossa crítica literária diga o contrário, os procedimentos artísticos têm pressupostos que não são artísticos eles próprios".

Mas para voltar ao começo deste texto, vale fazer um último comentário a respeito da noção de aura. A aura ganha conotação filosófica apenas a partir das mãos de Benjamin. A palavra "aura" vem do grego aúra e significa sopro, brisa, ar, vapor,

[...] sua ilustração como círculo dourado em torno da cabeça, tal como aparece em imagens religiosas, talvez derive da identificação vulgar entre o termo grego e o latino aureum (ouro), que deu origem à palavra auréola. Simbolicamente, entretanto, ambas (aura e auréola) indicam um procedimento universal de valorização sagrada ou sobrenatural de um personagem: a aura designa a luz em torno da cabeça dos seres dotados de força divina, sendo que a luz é sempre um índice de sacralização. (PALHARES 2006: 13).

Isto é, a aura remete a um vocabulário teológico e teosófico. Conforme sublinhou Gershon SchOLEM (apud KoTHE 1978: 41), “o conceito estava no vocabulário de todos os que se ocupavam com coisas teológicas. Designa a luz invisível que rodeia uma aparição, o prolongamento de todo o psicofísico de uma pessoa e que é visível ou pode se tornar visível para determinadas pessoas".

Não deixa de ser curioso, à primeira vista, como a noção de "aura", oriunda de um contexto religioso ganhe tamanho destaque num texto tão inspirado pelo marxismo tal como é "A obra de arte...". Mas podemos encontrar em Marx um uso similar da noção de aura. Em determinado momento do Manifesto Comunista, MARX (2007: 42) afirma que "A burguesia despojou de sua auréola todas as atividades até então reputadas como dignas e encaradas com piedoso respeito. [...] A burguesia rasgou o véu do sentimentalismo que envolvia as relações de família e reduziu-as a relações monetárias". Embora o termo "auréola" [Heiligenschein] seja diverso do termo utilizado por Benjamin, "aura”, poderíamos, talvez, estabelecer um paralelo entre as duas noções. Principalmente se pensarmos que Marx, assim como Benjamin, também dialogou com

aparece como um evento isolado, peculiar e dotado de certa arbitrariedade se torna permanente, a despeito de suas resistências.

Pandaemonium, São Paulo, v. 17, n. 24, Dez.. /2014, 37-52 
Lima, B. - Benjamin leitor de Brecht

questões religiosas ${ }^{6}$ e que uma arte sem aura pode ser entendida, dessa maneira, como uma arte liberada da magia - do mesmo modo como a revolução burguesa é entendida por Marx no Manifesto como espécie de dessacralização do mundo - e ainda que Benjamin compare a aura ao véu da beleza [schöner Schein] e esta mesma ideia de auréola e véu está presente em Marx ${ }^{7}$. De qualquer modo, o conceito de "aura" é de difícil rastreamento e um tema controverso para a fortuna crítica de Benjamin.

Mas apesar disso, penso que vale arriscar um palpite relativo à crítica que tanto Adorno quanto Brecht dirigem a Benjamin com relação a este conceito. A crítica de Brecht volta-se para o modo como Benjamin utiliza-se da contradição em sua explicação e menos ao conceito por si mesmo. Nesse sentido, o esclarecimento da mística, da mística enquanto mística, isto é, enquanto experiência especial, e a expressão específica "materialista" levada a sério poderiam ser resumidas a um problema de falta de clareza de Benjamin. Brecht atribui o misticismo a uma característica subjetiva de Benjamin, enquanto este busca compreender a aura enquanto experiência mística como uma tendência social objetiva e uma marca histórico-filosófica de época. A objeção de Adorno vai na mesma direção ao observar que, em Benjamin, esclarecimento e mito apresentam-se fundidos pela última vez.

O que Adorno e Brecht parecem ter dificuldade de compreender - aliás, este é um dos temas clássicos da sociologia - é que o místico é a experiência da aura e não seu conceito. A sociologia desde seus primórdios busca explicar a experiência mística, definir cientificamente aquilo que aparece a seus participantes como uma experiência do indefinível e, sem contradizer o seu caráter místico, encontrar nela seus fundamentos sociais. Tal como Marx faz com o fetichismo da mercadoria (a experiência mística por excelência do capitalismo), Durkheim faz com a religião e Weber com o leve manto protestante que se torna uma crosta de ferro. Marx, por exemplo, precisa recorrer a uma experiência mágico-religiosa para explicar como no núcleo do capitalismo, enquanto um sistema que se pretende plenamente racional, surge uma força que domina os homens e que lhes parece algo estranho: o fetichismo da mercadoria. E a palavra fetichismo não é utilizada por Marx à toa: tal como em algumas religiões a um objeto

\footnotetext{
${ }^{6}$ O próprio termo "fetiche" ou "fetichismo" foi retirado por Marx do reino obscuro e místico das religiões animistas e fetichistas. (Cf. MARX/ ENGELS 2007).

${ }^{7}$ Essa associação da aura e da "bela aparência" ou como "véu da beleza" aparece desenvolvida na nota de número dez da segunda versão de "A obra de arte..."
} 
Lima, B. - Benjamin leitor de Brecht

produzido pelo homem são atribuídas qualidades sobrenaturais, do mesmo modo no capitalismo os produtos do trabalho parecem adquirir poderes sobre seus produtores.

Assim como Marx demonstra o núcleo irracional do capitalismo, a noção de aura está diretamente ligada à noção de mito no pensamento benjaminiano. Como crítico do progresso tal como ficou conhecido, Benjamin sempre esteve interessado em mostrar essa dialética entre a sociedade racionalizada e a insistência do mito que a permeia. Em suma, mística é a coisa em si, ou seja, a própria experiência da aura, aquilo que sobrevive do mágico e do religioso numa sociedade cada vez mais racionalizada, e não a atitude ou método de Benjamin.

\section{Referências Bibliográficas}

ADORNO, Theodor W. "Carta de Theodor Adorno a Max Horkheimer de 21 de março de 1936" In:: Capistrano, T. (org.) Benjamin e a obra de arte: técnica, imagem, percepção. Rio de Janeiro: Contraponto, 2012.

BENJAMIN, Walter. "Conversations with Brecht". In:Understanding Brecht. New York, London: Verso, 1988. . Gesammelte Schriften Band II-2. Frankfurt am Main: Suhrkamp, 1989.

.Gesammelte Schriften Band I-2. Frankfurt am Main: Suhrkamp, 1991.

- "O autor como produtor". Em: Magia e Técnica, Arte e Política: ensaios sobre literatura e história da cultura. São Paulo: Brasiliense, 1994a.

. "Que é o teatro épico: um estudo sobre Brecht". Em: Magia e Técnica, Arte e Política: ensaios sobre literatura e história da cultura. São Paulo: Brasiliense, 1994b.

- A obra de arte na época de sua reprodutibilidade técnica. Apresentação, tradução e notas de Francisco de Ambrosis Pinheiro Machado. Porto Alegre: Zouk, 2012.

BRECHT, Bertolt. "O Teatro Experimental”. In: Teatro Dialético: Ensaios. Rio de Janeiro: Civilização Brasileira, 1967a.

. "O efeito de distanciamento nos atores chineses". Em: Teatro Dialético: Ensaios. Rio de Janeiro: Civilização Brasileira, 1967b.

.Diário de trabalho. Rio de Janeiro: Rocco, 2002, volume I.

BUCK-MorsS, Susan. "Estética e anestética: uma reconsideração de A obra de arte de Walter Benjamin". In: Capistrano, T. (org.) Benjamin e a obra de arte: técnica, imagem, percepção. Rio de Janeiro: Contraponto, 2012.

CANDIDO, Antonio. Literatura e Sociedade: Estudos de Teoria e História Literária. Rio de Janeiro: Ouro sobre Azul, 2008 (10 Edição Revista pelo autor).

CostA, Iná Camargo. Sinta o Drama. Petrópolis, RJ: Vozes, 1998.

JAMESON, Fredric. Brecht e a questão do método. São Paulo: Cosac Naify, 2013.

Kothe, Flávio. Benjamin \& Adorno: Confrontos. São Paulo: Ática, 1978.

LUKÁCS, Georg. História e Consciência de Classe: estudos sobre a dialética marxista. São Paulo: Martins Fontes, 2003.

MARX, Karl / Engels, Friedrich. Manifesto Comunista. São Paulo: Boitempo, 2007. 
Lima, B. - Benjamin leitor de Brecht

Palhares, Taisa Helena Pascale. Aura: a crise da arte em Walter Benjamin. São Paulo: Editora Barracuda, 2006.

SCHÖTTKER, Detlev. "Comentários sobre Benjamin e A obra de arte". In: Capistrano, T. (org.) Benjamin e a obra de arte: técnica, imagem, percepção. Rio de Janeiro: Contraponto, 2012.

SCHWARZ, Roberto. "Altos e baixos da atualidade de Brecht”. Em: Sequências Brasileiras. São Paulo: Companhia das Letras, 1999.

SzONDI, Peter. Teoria do Drama Moderno (1880-1950) São Paulo: Cosac Naify, 2011.

WeBER, Max. Economía y Sociedad: Esbozo de Sociología Comprensiva. México: Fondo De Cultura Económica, 1944.

Recebido em 11/03/2014

aceito em 27/08/2014 